11

\title{
Передача и преобразование электромагнитного излучения фотонно-кристаллическими металлодиэлектрическими системами на основе опалов
}

\author{
() А.И. Ванин ${ }^{1}$, Ю.А. Кумзеров ${ }^{1,2}$, С.Г. Романов $^{2}$, В.Г. Соловьев ${ }^{1,3,9}$, С.Д. Ханин ${ }^{3}$, \\ А.В. Цветков ${ }^{1}$, М.В. Яников ${ }^{1}$ \\ ${ }^{1}$ Псковский государственный университет, \\ 180000 Псков, Россия \\ ${ }^{2}$ ФТИ им. А.Ф. Иофрфе РАН, \\ 194021 Санкт-Петербург, Россия \\ ${ }^{3}$ Военная академия связи им. С.М. Буденного, \\ 194064 Санкт-Петербург, Россия \\ "e-mail: solovyev_v55@mail.ru
}

Поступила в редакцию 20.05.2020 г.

В окончательной редакции 20.05.2020 г.

Принята к публикации 07.07.2020 г.

Проведено экспериментальное исследование оптических свойств двух видов металлодиэлектрических композитов на основе опаловых матриц:

1) слоистых структур, полученных последовательным напылением металлических и диэлектрических пленок на монослой опаловых глобул, где обнаружено аномальное пропускание и поглощение света вследствие возбуждения поверхностных плазмон-поляритонов различных типов;

2) „массивных“ образцов опалов, в которые металл вводился методом электротермодиффузии, где наблюдалась асимметричная форма брэгговских резонансных кривых, обусловленная резонансом Фано.

Ключевые слова: фотонные кристаллы, опалы, поверхностные плазмон-поляритоны, металлодиэлектрические системы, резонанс Фано.

DOI: $10.21883 / \mathrm{OS} .2020 .12 .50330 .156-20$

\section{Введение}

Под фотонными кристаллами (ФК) понимают оптические материалы, обладающие пространственной периодичностью показателя преломления (ПП) $[1,2]$. В результате возникают запрещенные энергетические состояния для света с длиной волны, сопоставимой с периодом структуры, - фотонные запрещенные зоны (ФЗ3), что экспериментально проявляется в возникновении максимумов в спектрах отражения и коррелирующих с ними минимумов в спектрах пропускания. Возможность целенаправленно влиять на положение и ширину $\Phi 33$, выбирая используемый материал и меняя геометрию структуры, позволяет применять ФК на практике при изготовлении устройств, управляющих потоками электромагнитного (ЭМ) излучения.

В роли трехмерных ФК могут успешно выступать синтетические опалы, состоящие из одинаковых субмикронных сфер (глобул), образующих гранецентрированную кубическую решетку [3]. Поскольку фотонноэнергетическая структура (ФЭС) опала определяется особенностями его строения, необходимым условием расширения функциональных возможностей образца по управлению потоками ЭМ излучения является ее модификация. Диспергирование различных веществ в опаловых матрицах [4], обладающих регулярной системой полостей первого и второго порядков [5], позволяет осуществлять модификацию ФЭС вследствие изменения функции распределения ПП входящих в состав образца компонент.

Модификацию ФЭС ФК можно также осуществить путем гибридизации собственных фотонных мод опала с волнами рассеяния на дефектах кристалла или возбуждения плазмонных резонансов при введении наночастиц металлического наполнителя [6,7].

Альтернативным вариантом построения гибридных систем является создание металлодиэлектрических плазмонно-фотонных гетерокристаллов (ПФГК), состоящих из различных комбинаций слоев коллоидных ФК в контакте с тонкопленочными плазмонными кристаллами [8]. В этом случае функциональные возможности управления потоками ЭМ излучения (как и возможности управления движением электронов) значительно расширяются благодаря дополнительным эффектам переноса энергии вдоль границы металл-диэлектрик за счет поверхностных плазмон-поляритонов (ППП) [9-11]. Практическая реализация подобных структур возможна в случае, если морфология связного металлического покрытия отвечает решетке исходного ФК.

Цель данной работы, продолжающей предшествующие исследования [12-15], - детализировать информацию об оптических явлениях, происходящих в двух ти- 


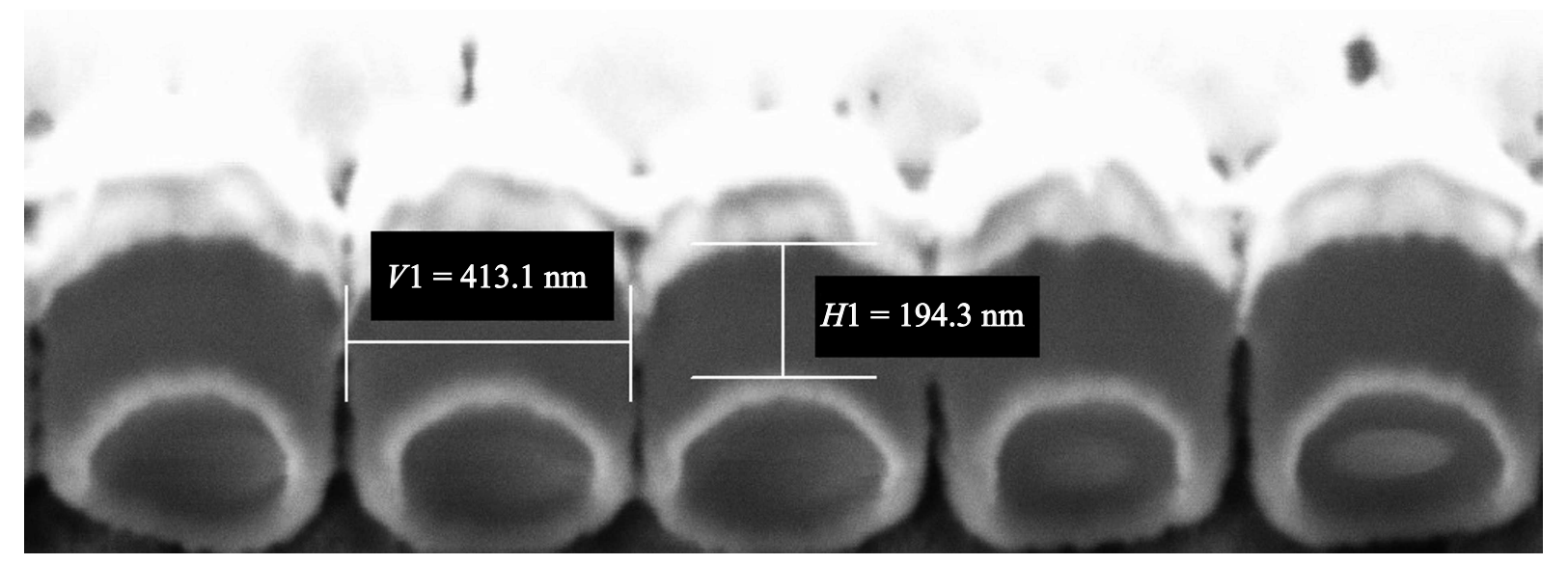

Рис. 1. Электронно-микроскопическое изображение поперечного сечения образца гибридного плазмонно-фотонного кристалла $\mathrm{Ag} / \mathrm{SiO}_{2} / \mathrm{Ag} / \mathrm{ML} / \mathrm{Ag}$.

пах фотонно-кристаллических металлодиэлектрических структур на основе опалов:

1) в слоистых металлодиэлектрических структурах, полученных последовательным напылением металлических и диэлектрических пленок на монослой (ML) опаловых глобул;

2) в нанокомпозиционных материалах $\mathrm{Ag} /$ опал или $\mathrm{Sn} /$ опал на основе „массивных“опаловых матриц, в которые металл вводился методом электротермодиффузии.

\section{Экспериментальная часть}

В настоящей работе исследованы оптические свойства слоистых тонкопленочных гетероструктур $\mathrm{Ag} / \mathrm{SiO}_{2} / \mathrm{Ag} / \mathrm{ML} / \mathrm{Ag}$ и „массивных“ образцов нанокомпозитов Ме/опал $(\mathrm{Me}=\mathrm{Ag}, \mathrm{Sn})$.

Образцы $\mathrm{Ag} / \mathrm{SiO}_{2} / \mathrm{Ag} / \mathrm{ML} / \mathrm{Ag}$ получены посредством последовательного нанесения металлических (Ag) и диэлектрических $\left(\mathrm{SiO}_{2}\right)$ пленочных покрытий заданной толщины на монослой (ML) опаловых глобул из полиметилметакрилата (ПММА) методом магнетронного распыления на установке ATC ORION SERIES SPUTTERING SYSTEM. В качестве контрольного образца использовался резонатор Фабри-Перо (интерференционный фильтр) $\mathrm{Ag} / \mathrm{SiO}_{2} / \mathrm{Ag}$ со слоем диэлектрика такой же толщины, отдельно сформированный на плоской поверхности.

Изображение поперечного сечения образца $\mathrm{Ag} / \mathrm{SiO}_{2} / \mathrm{Ag} / \mathrm{ML} / \mathrm{Ag}$ (рис. 1) получено после его обработки сфокусированным пучком ионов аргона на сканирующем электронном микроскопе ZEISS FIB-SEM GEMINI.

Опыт показал [13-15]), что наружная поверхность тонкого слоя вещества, покрывающего опаловые глобулы, сохраняла форму и пространственную периодичность, характерную для границы раздела между опалоподобной пленкой и этим слоем.
Нанокомпозиты Ме/опал получены введением металла (серебра или олова) в „массивные“ образцы опаловых матриц методом электротермодиффузии при значениях напряженности постоянного электрического поля $E=1.10-3.75 \mathrm{kV} / \mathrm{cm}$. Введение серебра осуществлялось при температурах $T=660-800 \mathrm{~K}$, введение олова - при $T=500 \mathrm{~K}$.

Спектры пропускания $s$ - и $p$-поляризованного света слоистыми тонкопленочными гетероструктурами (когда вектор напряженности электрического поля ЭМ волны перпендикулярен или параллелен плоскости падения соответственно) исследовались с угловым разрешением с помощью экспериментальной установки на базе спектрометра Ocean Optics QE65000. Для изучения спектров отражения естественного света „массивными“ металлодиэлектрическими образцами на основе опалов использовалась установка на базе спектрометра USB650 Red Tide.

\section{Результаты и их обсуждение}

На рис. 2, $а$ представлены спектры пропускания исследованных в работе тонкопленочных слоистых металлодиэлектрических структур при нормальном падении света. Монослой опаловых глобул, выращенный на стеклянной подложке, взаимодействует со светом подобно двумерной дифракционной решетке. Вместе с тем, как показано в работе [16], локализация ЭМ поля в монослое позволяет рассматривать его как плоский волновод. Эти два возможных сценария взаимодействия ЭМ волн с монослоем (поверхностная дифракция света и волноводные резонансы) и определяют сложный характер спектра пропускания $T_{1}(\lambda)$ монослоя (рис. 2, $a$, кривая 1). При этом наиболее интенсивный минимум пропускания (расположенный на кривой 1 при $509 \mathrm{~nm}$ ) c ростом угла падения сдвигается в область более длинных волн. При малых углах падения положение этого минимума позволяет по известным формулам, 

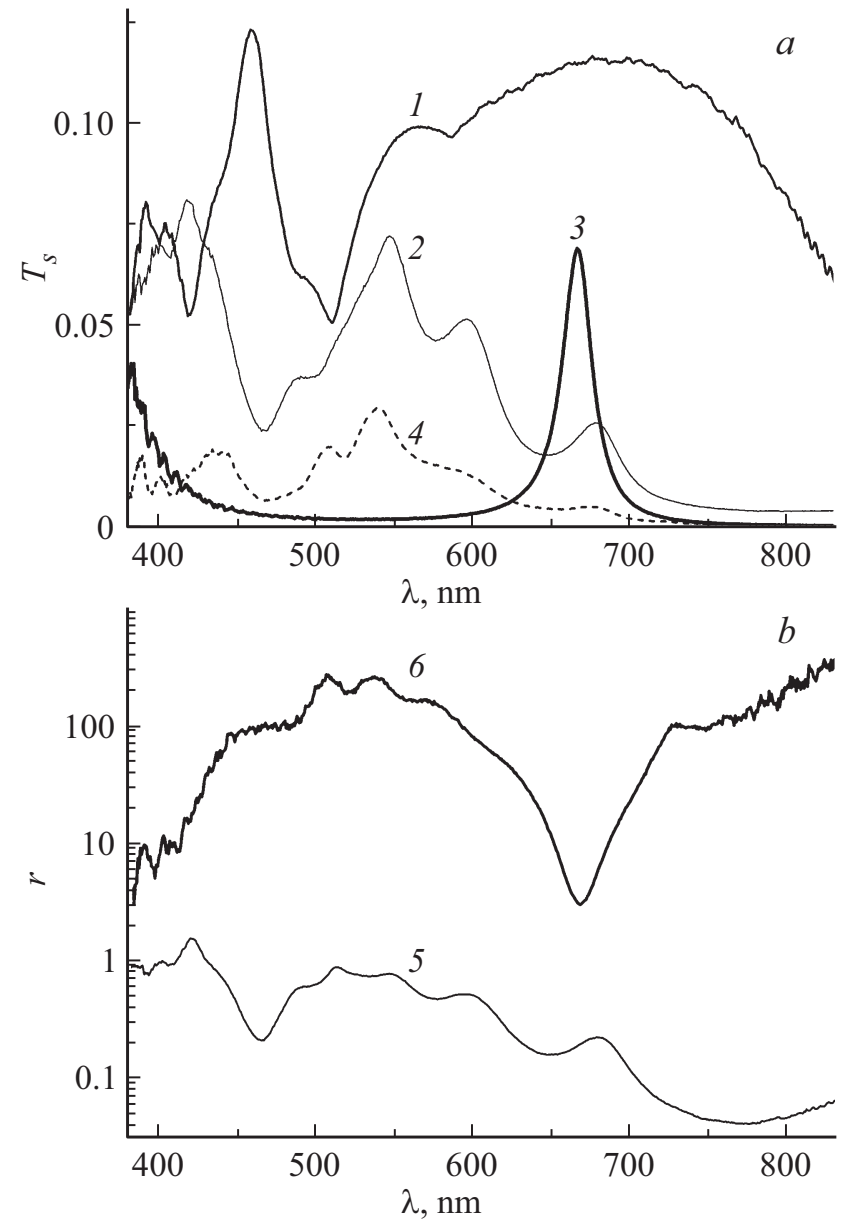

Рис. 2. (a) Спектры пропускания монослоя опаловых глобул $\left(T_{1}(\lambda)\right.$, кривая 1$)$, плазмонно-фотонного кристалла $\mathrm{Ag} / \mathrm{ML} / \mathrm{Ag} \quad\left(T_{2}(\lambda), \quad\right.$ кривая 2), резонатора $\mathrm{Ag} / \mathrm{SiO}_{2} / \mathrm{Ag}$ $\left(T_{3}(\lambda)\right.$, кривая 3), гибридного плазмонно-фотонного кристалла $\mathrm{Ag} / \mathrm{SiO}_{2} / \mathrm{Ag} / \mathrm{ML} / \mathrm{Ag}\left(T_{4}(\lambda)\right.$, кривая 4) при нормальном падении света. (b) Отношения $r_{5}(\lambda)=T_{2}(\lambda) / T_{1}(\lambda)$ (кривая 5) и $r_{6}(\lambda)=T_{4}(\lambda) /\left(T_{2}(\lambda) T_{3}(\lambda)\right)$ (кривая 6 ).

описывающим возбуждение поверхностных ЭМ волн на периодической структуре $[9,16,17]$, оценить ее период: $d \approx \frac{\lambda}{n_{\text {eff }}}$, где $n_{\text {eff }} \approx 1.32-$ эффективный показатель преломления монослоя, который можно определить из соотношения: $n_{\text {eff }}^{2}=f n_{\mathrm{PMMA}}^{2}+(1-f) n_{\text {air }}^{2}$, где показатель преломления опаловых глобул $n_{\text {РммА }} \approx 1.49$, а их объемная доля в монослое $f=\frac{\pi}{3 \sqrt{3}}$. Полученное значение $d \approx 385 \mathrm{~nm}$ находится в разумном согласии с одним из параметров двумерной дифракционной решетки [16]: $a=\frac{D \sqrt{3}}{2} \approx 357 \mathrm{~nm}$, где в соответствии с данными электронной микроскопии (рис. 1) диаметр опаловых глобул $D \approx 413 \mathrm{~nm}$.

Как показывает эксперимент, вблизи минимумов в спектрах пропускания монослоя наблюдается поляризационная анизотропия: коэффициент пропускания света $T_{p}$, имеющего ориентацию вектора напряженности электрического поля в плоскости падения ЭМ волны, примерно вдвое превышает коэффициент пропускания света $T_{s}$, для которого электрический вектор перпендикулярен этой плоскости. Подобные явления наблюдались ранее в пленках опалов в работе [18] и связывались с более сильным ослаблением $s$-поляризованного света в образцах.

Если монослой опаловых глобул поместить между двумя тонкими пленками металлического серебра (т.е. создать систему $\mathrm{Ag} / \mathrm{ML} / \mathrm{Ag}$ ), то наряду с ожидаемым небольшим уменьшением величины оптического пропускания системы в соответствующем спектре $T_{2}(\lambda)$ мы обнаруживаем также наиболее заметные пики пропускания при 597 и $547 \mathrm{~nm}$ (рис. 2, $a$, кривая 2). Этот эффект аномального пропускания (extraordinary transmission, ЕОТ), по-видимому, обусловлен возбуждением поверхностных плазмон-поляритонов (ППП), распространяющихся вдоль границ раздела “профилированный слой серебра-монослой опаловых глобул“ и „профилированный слой серебра-воздух“ соответственно. Отметим, что пик пропускания вблизи $400 \mathrm{~nm}$ (рис. 2, $a$, кривая 2), вероятно, связан с межзонными переходами в металлическом серебре $[10,11,19]$.

График функции $r_{5}(\lambda)=T_{2}(\lambda) / T_{1}(\lambda)$ (рис. $2, b$, кривая 5) иллюстрирует относительные изменения спектра пропускания, вызванные пленками серебра, между которыми располагается монослой опаловых глобул.

Однако наиболее интересные эффекты (как и в случаях, рассмотренных нами ранее в работах $[13,14])$ возникают при последовательном соединении с системой $\mathrm{Ag} / \mathrm{ML} / \mathrm{Ag}$ оптического резонатора $\mathrm{Ag} / \mathrm{SiO}_{2} / \mathrm{Ag}$, в спектре пропускания которого $T_{3}(\lambda)$ обнаруживается резкий пик при $667 \mathrm{~nm}$ (рис. 2, $a$, кривая 3). В спектре $T_{4}(\lambda)$ полученного при этом гибридного плазмонно-фотонного кристалла $\mathrm{Ag} / \mathrm{SiO}_{2} / \mathrm{Ag} / \mathrm{ML} / \mathrm{Ag}$ наблюдается дальнейшее падение коэффициента пропускания, имеющее селективный характер: в наибольшей степени пропускание уменьшается как раз в области максимального пропускания резонатора (рис. 2, $a$, кривая 4). Это убедительно демонстрирует график функции $r_{6}(\lambda)=T_{4}(\lambda) /\left(T_{2}(\lambda) T_{3}(\lambda)\right)$ (рис. 2, $b$, кривая 6).

В идеальном случае для последовательно расположенных друг за другом „пассивных“ оптических элементов при отсутствии взаимодействия между ними имело бы место соотношение $T_{4}(\lambda)=T_{2}(\lambda) T_{3}(\lambda)$, так что отношение $r_{6}$ равнялось бы единице. В действительности, как показывает рис. $2, b$, наблюдается отчетливая спектральная зависимость $r_{6}(\lambda)$, причем на графике наряду с небольшими максимумами возникает глубокий минимум пропускания, или максимум аномального поглощения, который по аналогии можно назвать „еxtraordinary absorption“, EОА. Подчеркнем, что спектральное положение ЕОА отвечает максимуму в спектре пропускания резонатора $\mathrm{Ag} / \mathrm{SiO}_{2} / \mathrm{Ag}$, что подтверждают рис. 3 и 4 , где представлена угловая дисперсия положения этих экстремумов для двух резонаторов с разной толщиной диэлектрического слоя. 
Отметим, что расщепление полосы пропускания интерференционного фильтра (рис. 3), обусловленное, повидимому, различием в фазовых сдвигах при отражении от слоя серебра $s$ - и $p$-компонент светового пучка, наблюдалось еще в ранних классических работах [20].

Эксперименты, проведенные нами по той же схеме с аналогичным гибридным плазмонно-фотонным кристаллом $\mathrm{Au} / \mathrm{SiO}_{2} / \mathrm{Au} / \mathrm{ML} / \mathrm{Au}$, где серебро было заменено на золото, оказались неудачными, по-видимому, вследствие высокого поглощения света в области межзонных переходов (в золоте эта область начинается с $2 \mathrm{eV}$, тогда как в серебре - лишь с $4 \mathrm{eV}[9,10])$. Не удалось также наблюдать аномальное оптическое поглощение в ПФГК $\mathrm{Ag} / \mathrm{ML} / \mathrm{Ag} / \mathrm{SiO}_{2} / \mathrm{Ag}$, когда монослой опаловых глобул выращивался на плоской (а не профилированной, необходимой для образования поверхностных плазмонполяритонов) поверхности резонатора $\mathrm{Ag} / \mathrm{SiO}_{2} / \mathrm{Ag}$, предварительно сформированного на стеклянной подложке.

Перейдем теперь к рассмотрению металлодиэлектрических структур другого типа - нанокомпозитов Ме/опал, полученных введением металла в „массивный“ образец опаловой матрицы методом электротермодиффузии.

Как показывает опыт, форма оптических спектров отражения нанокомпозита $\mathrm{Ag}$ /опал существенно зависит от условий введения серебра в опаловую матрицу. При этом в наших экспериментах наблюдались два различных случая.

При сравнительно небольшой напряженности электрического поля $(E \approx 1.1 \mathrm{kV} / \mathrm{cm})$, при которой происходила электротермодиффузия, плотность тока, протекающего через образец с прижимными серебряными элек-

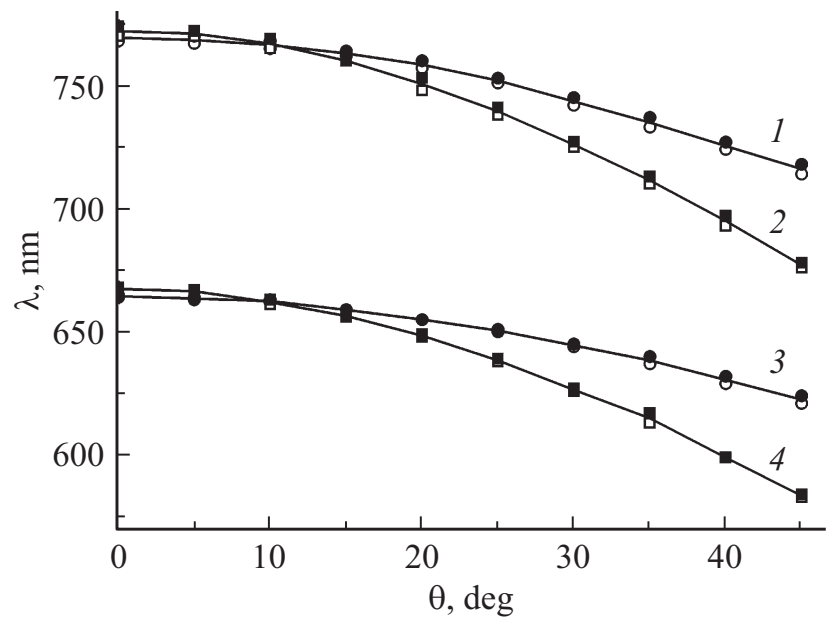

Pис. 3. Угловая дисперсия максимумов первого порядка в спектрах пропускания резонаторов (интерференционных фильтров) $\mathrm{Ag} / \mathrm{SiO}_{2} / \mathrm{Ag}$ (светлые кружки и квадраты) и минимумов в спектральных зависимостях отношения $r_{6}(\lambda)=T_{4}(\lambda) /\left(T_{2}(\lambda) T_{3}(\lambda)\right)$ (темные кружки и квадраты) при различных значениях толщины диэлектрического слоя резонатора $(1,2-250 \mathrm{~nm} ; 3,4-194 \mathrm{~nm})$ и различных поляризациях падающего света $(1,3-p$-поляризация; $2,4-s$ поляризация).
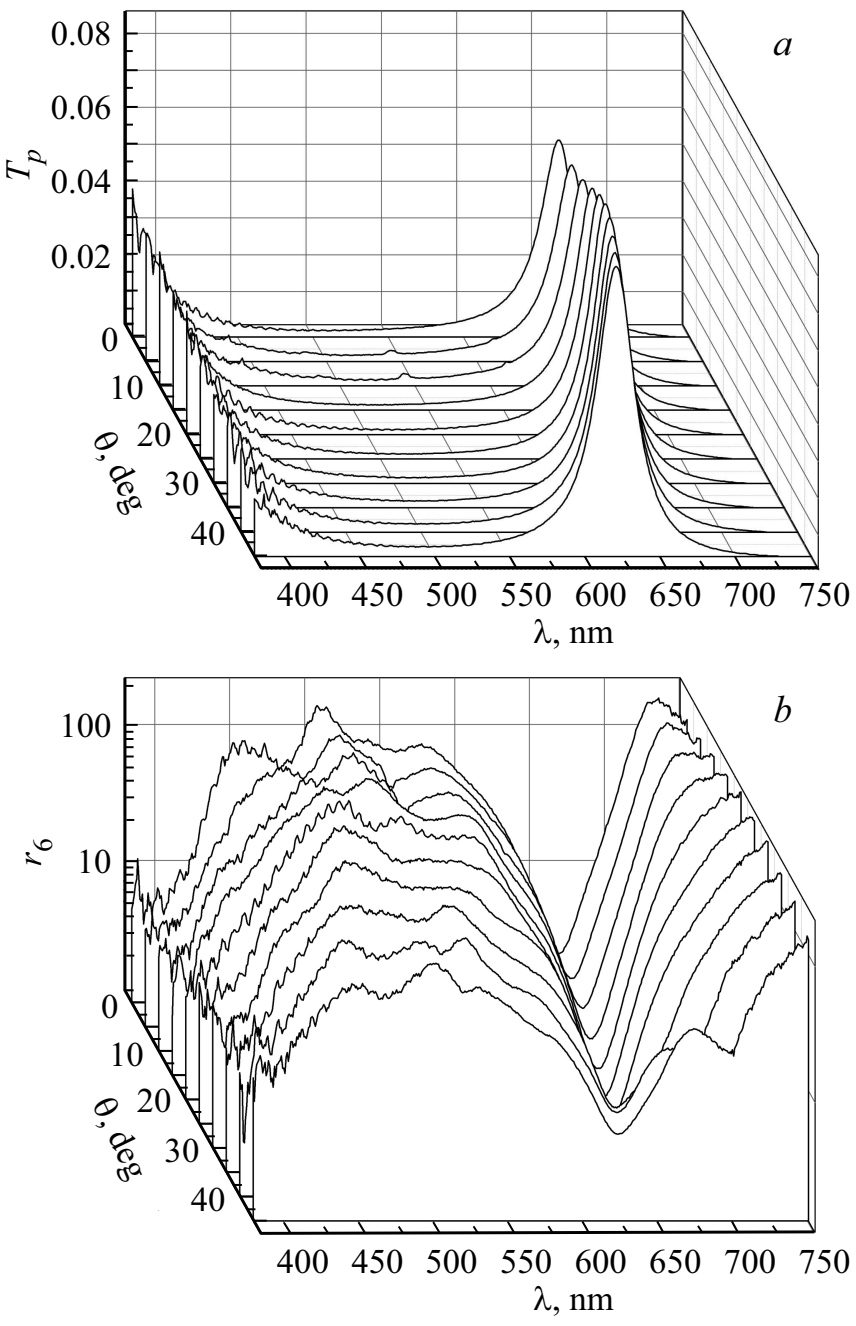

Pис. 4. (а) Спектры пропускания резонатора $\mathrm{Ag} / \mathrm{SiO}_{2} / \mathrm{Ag}$ с толщиной диэлектрического слоя $194 \mathrm{~nm}$ при различных углах падения света $\theta$ на образец ( $p$-поляризация). (b) Отношение $r_{6}(\lambda)=T_{4}(\lambda) /\left(T_{2}(\lambda) T_{3}(\lambda)\right)$, определяющее положение ЕОА при различных углах падения света $\theta$ на образец ( $p$-поляризация).

тродами при температуре $T \approx 700 \mathrm{~K}$, почти не меняла своего значения $\left(j \approx 2.5 \mu \mathrm{A} / \mathrm{cm}^{2}\right)$ на протяжении всего времени опыта $(t=4 \mathrm{~h})$.

В этом случае в спектрах отражения нанокомпозита $\mathrm{Ag} /$ ппал наряду с полосой исходной опаловой матрицы возникала более слабая длинноволновая полоса (рис. 5), связанная предположительно с появлением наночастиц серебра на поверхности (или внутри - в порах второго порядка) некоторых опаловых глобул.

С другой стороны, при увеличении напряженности электрического поля в образце до значений $E \approx 1.7 \mathrm{kV} / \mathrm{cm}$ плотность тока при тех же температурах возрастала в процессе электролиза в 500 раз (от $j_{1} \approx 2.6 \mu \mathrm{A} / \mathrm{cm}^{2}$ до $j_{2} \approx 1.3 \mathrm{~mA} / \mathrm{cm}^{2}$ ). При этих условиях в образце возможно образование дендритов, рассеяние света на которых может приводить к несим- 


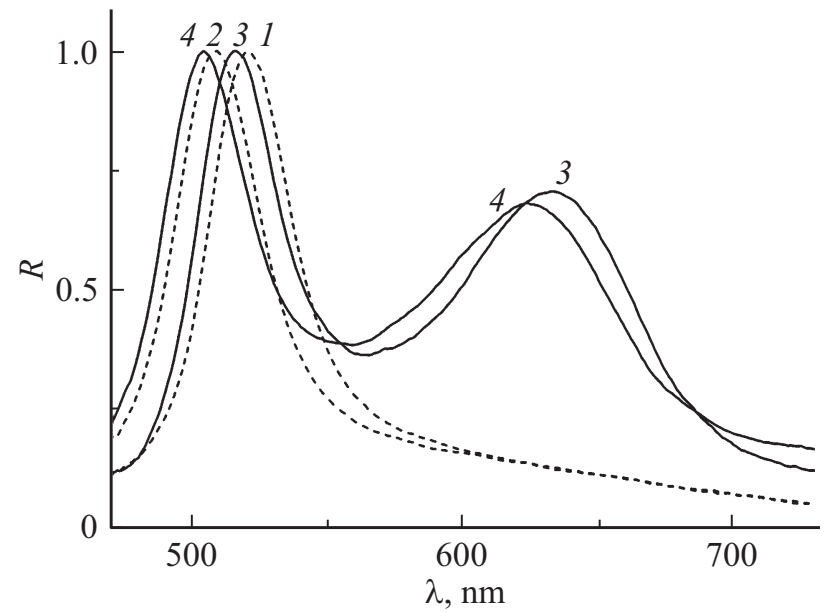

Рис. 5. Нормированные спектры отражения исходной матрицы опала $(1,2)$ и нанокомпозита $\mathrm{Ag} /$ опал $(3,4)$, полученного методом электротермодиффузии при небольших плотностях тока, измеренные при углах падения света $25^{\circ}(1,3)$ и $30^{\circ}(2,4)$.

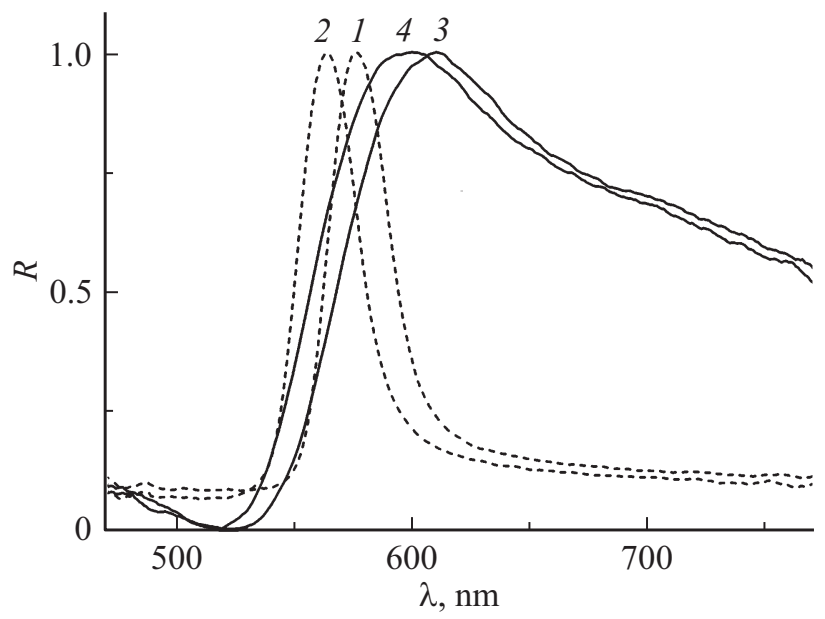

Рис. 6. Нормированные спектры отражения исходной матрицы опала $(1,2)$ и нанокомпозита $\mathrm{Ag} /$ опал $(3,4)$, полученного методом электротермодиффузии при больших плотностях тока, измеренные при углах падения света $25^{\circ}(1,3)$ и $30^{\circ}(2,4)$.

метричности полос в спектрах отражения нанокомпозита $\mathrm{Ag}$ /опал (рис. 6). Подобный несимметричный профиль характерен для резонанса Фано [21], который ранее наблюдался на брэгговских линиях в оптических спектрах чистых (без примесей) синтетических опалов в работах [22-24]. Как следует из сравнения кривых 3 и 4 с кривыми 1 и 2 (рис. 6), введение серебра в опаловую матрицу приводит к яркому проявлению резонанса Фано, который может быть описан теоретически [25] на основе модельных представлений об интерференции двух ЭМ волн. В данном случае в роли одной из них, по-видимому, выступает узкополосное излучение, обусловленное брэгговской дифракцией в ФК, а вторая представляет собой широкополосное излучение, возникающее в результате рассеяния на случайных нарушени- ях структуры матрицы опала и неоднородностях (дендритах), образующихся в местах проникновения серебра в трехмерную систему взаимосвязанных пор опаловой матрицы, что убедительно подтверждают соответствующие электронно-микроскопические изображения $[13,14]$.

Аналогичные (хотя и менее ярко выраженные) эффекты наблюдались нами и в нанокомпозитах Sn/опал [26], полученных введением олова в опаловую матрицу при напряженности электрического поля $E \approx 1.9 \mathrm{kV} / \mathrm{cm}$ и температуре $500 \mathrm{~K}$ (на $5 \mathrm{~K}$ ниже точки плавления „массивного“ $\mathrm{Sn}$ ). Отметим, что формирование микро- и нанодендритов из Sn в нанопористом стекле в результате электролиза наблюдалось ранее в работе [27].

Как видно из рис. 7, демонстрирующего „синий“ сдвиг максимумов в спектрах отражения, представленных на рис. 5 и 6, при увеличении угла падения $\theta$ наблюдается линейная зависимость $\lambda^{2}=f\left(\sin ^{2} \theta\right)$, отвечающая известному соотношению, которое легко получить из законов Вульфа-Брэггов (для резонанса первого порядка) и Снеллиуса:

$$
\lambda^{2}=4 d^{2}-4 d^{2} \sin ^{2} \theta
$$

где $d=0.816 D-$ межплоскостное расстояние для плоскостей (111) ГЦК структуры опала, $D$ - диаметр опаловых глобул.

Заметим, однако, что в случаях, когда исходная опаловая матрица обладала частичным разупорядочением, представляя собой так называемое „фотонное стекло“, в соответствующих спектрах отражения нами наблюдались также и максимумы отражения, положение которых не менялось при увеличении угла падения света на образец [13].

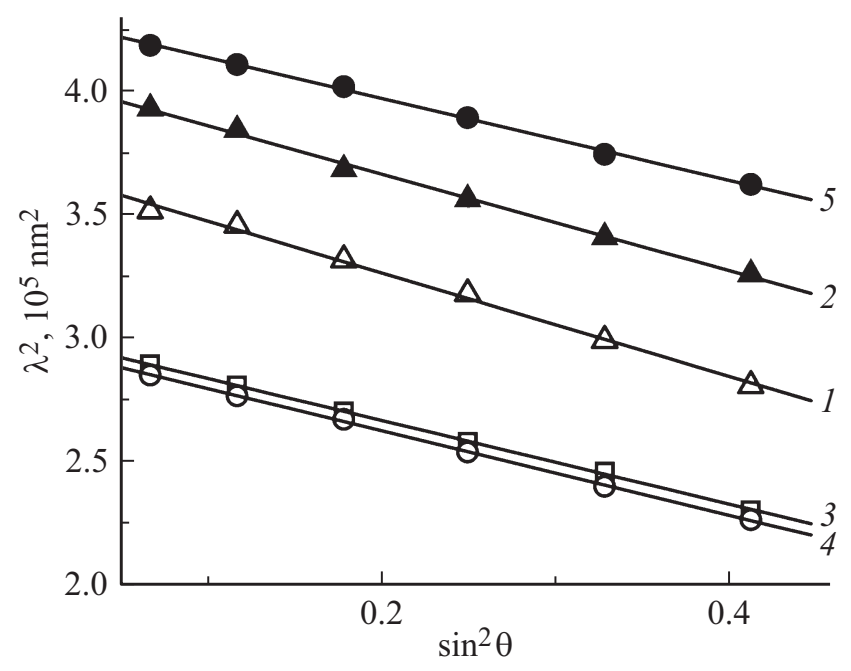

Рис. 7. Угловая дисперсия брэгговского резонанса первого порядка для исходных опаловых матриц с диаметрами глобул $288(1), 251 \mathrm{~nm}(3)$ и нанокомпозитов $\mathrm{Ag} /$ опал, полученных введением серебра в матрицу опала методом электротермодиффузии при значениях напряженности электрического поля 1.7 (2) и $1.1 \mathrm{kV} / \mathrm{cm}(4,5)$. 


\section{Заключение}

В работе представлены и проанализированы результаты экспериментального исследования процессов передачи и преобразования электромагнитного излучения в полученных авторами двух типах металлодиэлектрических фотонно-кристаллических композиционных систем на основе опалов: 1) слоистых металлодиэлектрических гетероструктурах, сформированных путем последовательного напыления металлических и диэлектрических пленок на опалоподобные монослои, и 2) „массивных“ образцов синтетических опалов, в которые металл вводился методом электротермодиффузии.

В оптических спектрах слоистых плазмонно-фотонных гетероструктур наряду с аномальным пропусканием света обнаружено также его интенсивное аномальное поглощение, что связано, по-видимому, с возбуждением на границах раздела „профилированный слой металла-монослой опаловых глобул“ поверхностных плазмон-поляритонов различных типов.

Положение оптических резонансов нанокомпозитов, полученных введением металла в опаловую матрицу методом электротермодиффузии, обусловлено брэгговской дифракцией, а асимметричная форма резонансных кривых - резонансом Фано.

Полученные результаты могут представлять интерес для разработчиков при создании оптических систем, управляющих потоками электромагнитного излучения, в фотонике и наноплазмонике.

\section{Финансирование работы}

Работа выполнена при финансовой поддержке Германской службы академических обменов (DAAD) и РФФИ в рамках научного проекта № 20-32-90003.

\section{Благодарность}

Авторы признательны М.И. Самойловичу, У. Пешелю и Д. Плоссу за предоставление образцов для исследования, полезные обсуждения и помощь в проведении экспериментов.

\section{Конфликт интересов}

Авторы заявляют, что у них нет конфликта интересов.

\section{Список литературы}

[1] Joannopoulos J.D., Meade R.D., Winn J.N. Photonic Crystals: Molding the Flow of Light. Princeton University Press, 2008. $286 \mathrm{p}$.

[2] Photonic crystals: Advances in design, fabrication, and characterization / Ed. by Busch K., Lölkes S., Wehrspohn R.B., Föll H. Wiley-VCH, 2004. 354 p.

[3] Балакирев В.Г., Богомолов В.Н., Журавлев В.В., Кумзеров Ю.А., Петрановский В.П., Романов С.Г., Самойлович Л.А. // Кристаллография. 1993. Т. 38. № 3. С. 111.
[4] Astratov V.N., Bogomolov V.N., Kaplyanskii A.A., Prokofiev A.V., Samoilovich L.A., Samoilovich S.M., Vlasov Yu.A. // Il Nuovo Cimento. 1995. V. 17D. P. 1349.

[5] Богомолов В.Н., Парфеньева Л.С., Прокофьев А.В., Смирнов И.А., Самойлович С.М., Ежовский А., Муха Я., Мисерек X. // ФТТ. 1995. Т. 37. № 11. С. 3411.

[6] Горелик В.С. // ФТТ. 2009. Т. 51. № 7. С. 1252; Gorelik V.S. // Physics Solid State. 2009. V. 51. N 7. P. 1321.

[7] Саласюк А.С., Щербаков А.В., Акимов А.В., Грудинкин С.А., Дукин А.А., Каплан С.Ф., Певцов А.Б., Голубев В.Г. // ФТТ. 2010. Т. 52. № 6. C. 1098; Salasyuk A.S., Shcherbakov A.V., Akimov A.V., Grudinkin S.A., Dukin A.A., Kaplan S.F., Pevtsov A.B., Golubev V.G. // Phys. Sol. State. 2010. V. 52. N 6. P. 1170.

[8] Romanov S.G., Korovin A., Regensburger A., Peschel U. // Advanced Materials. 2011. V. 23. P. 2515.

[9] Поверхностные поляритоны (Электромагнитные волны на поверхностях и границах раздела сред) / Под ред. Аграновича В.М., Миллса Д.Л. М.: Наука, 1985. 526 с.

[10] Maier S.A. Plasmonics: Fundamentals and Applications. NY: Springer, 2007. $223 \mathrm{p}$.

[11] Климов В.В. Наноплазмоника. М.: Физматлит, 2010. 480 с.

[12] Veisman V.L., Romanov S.G., Solovyev V.G., Yanikov M.V. // Environment. Technology. Resources: Proceedings of the $10^{\text {th }}$ International Scientific and Practical Conference. Rëzekne, Latvia, 2015. V. 1. P. 230. doi 10.17770/etr2015vol1.197

[13] Cvetkov A.V., Gerbreders V.I., Khanin S.D., Lukin A.E., Ogurcovs A.S., Romanov S.G., Solovyev V.G., Vanin A.I., Yanikov M.V. // Environment. Technology. Resources: Proceedings of the 11th International Scientific and Practical Conference. Rëzekne, Latvia, 2017. V. III. P. 37. doi 10.17770/etr2017vol3.2660

[14] Ванин А.И., Лукин А.Е., Романов С.Г., Соловьев В.Г., Ханин С.Д., Яников М.В. // ФТТ. 2018. Т. 60. № 4. C. 770; Vanin A.I., Lukin A.E., Romanov S.G., Solovyev V.G., Khanin S.D., Yanikov M.V. // Phys. Sol. State. 2018. V. 60. N 4. P. 774.

[15] Алексеева Н.О., Вейсман В.Л., Лукин А.Е., Панькова С.В., Соловьев В.Г., Яников М.В. // Нанотехника. 2012. № 3 (31). C. 23.

[16] Романов С.Г. // ФТТ. 2017. Т. 59. № 7. С. 1329; Romanov S.G. // Phys. Sol. State. 2017. V. 59. N 7. P. 1356.

[17] Физическая энциклопедия / Главный редактор А.М. Прохоров. М.: Большая Российская энциклопедия, 1992. Т. 3. C. 651 .

[18] Романов С.Г. // ФТТ. 2010. Т. 52. № 4. С. 788; Romanov S.G. // Phys. Sol. State. 2010. V. 52. N 4. P. 844.

[19] Борн М., Воль $\varnothing$ Э. Основы оптики. М.: Наука, 1970. 856 с.; Born M., Wolf E. Principles of optics. Oxford: Pergamon Press, 1964.

[20] Розенберг Г.В. Оптика тонкослойных покрытий. М.: Физматгиз, 1958. $570 \mathrm{c}$.

[21] Fano U. // Phys. Rev. 1961. V. 124. P. 1866.

[22] Rybin M.V., Khanikaev A.B., Inoue M., Samusev K.B., Steel M.J., Yushin G., Limonov M.F. // Phys. Rev. Lett. 2009. V. 103. P. 023901.

[23] Rybin M.V., Khanikaev A.B., Inoue M., Samusev A.K., Steel M.J., Yushin G., Limonov M.F. // Photonics and Nanostructures - Fundamentals and Applications. 2010. V. 8. P. 86. 
[24] Limonov M.F., Rybin M.V., Poddubny A.N., Kivshar Y.S. // Nature Photonics. 2017. V. 11. P. 543.

[25] Ванин А.И., Соловьев В.Г. // VI Международная конференция по фотонике и информационной оптике: Сборник научных трудов. М.: НИЯУ МИФИ, 2017. С. 140.

[26] Ванин А.И., Панькова С.В., Соловьев В.Г., Цветков А.В., Яников М.B. // IX Международная конференция по фотонике и информационной оптике: Сборник научных трудов. М.: НИЯУ МИФИ, 2020. С. 573.

[27] Сидоров А.И., Тунг Нго Дуи, Ву Нго Ван, Антропова Т.В., Нащекин А.В. // Опт. и спектр. 2019. Т. 127. № 5. С. 841; Sidorov A.I., Tung Ngo Dui, Wu Ngo Van, Antropova T.V., Nashchekin A.V. // Opt. Spectrosc. 2019. V. 127. N 5. P. 914. doi 10.21883/OS.2019.11.48525.135-19 